\title{
A Shear Strength Model for a Subsidence Backfill Body Based on Adhesion Friction Theory
}

\author{
Lei Liu $\mathbb{D}^{1,2}$ Shengyou Zhang $\mathbb{D}^{1,2}$ Weidong Liu $\mathbb{D}^{3},{ }^{3}$ Wei Sun $\mathbb{D}^{1,2}$ and Jinxin ${ }^{1, i}{ }^{1}$ \\ ${ }^{1}$ Faculty of Land Resources Engineering, Kunming University of Science and Technology, Kunming 650093, China \\ ${ }^{2}$ Yunnan Key Laboratory of Sino-German Blue Mining and Utilization of Special Underground Space, Kunming 650093, China \\ ${ }^{3}$ No. 3 Mining District of Jinchuan Group Co. Ltd., Jinchang 737103, China \\ Correspondence should be addressed to Wei Sun; kgblasting@qq.com
}

Received 18 March 2020; Revised 30 June 2020; Accepted 14 July 2020; Published 30 July 2020

Academic Editor: Hailing Kong

Copyright $\odot 2020$ Lei Liu et al. This is an open access article distributed under the Creative Commons Attribution License, which permits unrestricted use, distribution, and reproduction in any medium, provided the original work is properly cited.

\begin{abstract}
Proper determination of the shear strength of the backfill body used to fill the subsidence is the basis for subsidence restoration and the stability analysis of materials. This study developed a shear strength calculation model for the backfill body by introducing adhesive friction theory into the shear strength analysis. A direct shear test was performed in the laboratory to verify the proposed method. Test results suggested that the shear strength calculation method based on adhesive friction theory can calculate the variation in the actual contact area between grains in the tested samples undergoing shearing and estimate the peak shear strength. The actual contact area was divided into two components, namely, adhesive contact area $A_{\mathrm{rm}}$ and contact area reduction caused by shear displacement, which exhibited a maximum at $A_{\mathrm{rmax}}$. The shear strength values calculated by this method were smaller than laboratory values, and their differences increased with the rock proportion in the backfill body. The differences between the theoretical and experimental values of shear strength increased with the rock grain size. The results of theoretical calculation, combined with the results of laboratory experiments, can provide support for the proper determination of shear strength of the backfill body.
\end{abstract}

\section{Introduction}

Mining-induced subsidence has accounted for $50 \%$ of the total geological disasters caused by mining in China and affected an area of $314765 \mathrm{hm}^{2}$. This condition has attracted widespread attention and required the effective reclamation of subsided lands $[1,2]$. Traditionally, subsidence areas in mines act as disposal sites of solid wastes from the mines. In the recent years, new methods for reclaiming subsidence areas, such as filling subsidence areas with rocks blasted from surrounding mountains or with filter cakes made of tailings and converting these areas to tailing ponds, have emerged $[3,4]$. These methods are effective for subsided grounds free from mining influence (which indicates that no mining activity occurs in the underlying strata), but are unsuitable for subsided grounds that are still affected by mining activities in the underlying strata [5-7]. Waste rocks and tailings in a mine in Guangxi Province are manufactured into a paste to fill the subsidence area, which is in an active state. The amount of fill required is estimated to be 5 million $\mathrm{m}^{3}$. Considering that this area is subject to mining influence, reasonable mechanical properties of backfill body play a critical role in its successful restoration.

Existing studies have investigated the mechanical properties of fills for subsidence areas primarily through laboratory experiments and numerical simulations because subsidence areas are often dangerous. The research of Leduc and Smith on the mechanical properties of waste rock-tailing mixture discharged into a subsidence area indicated that the internal friction angle between grains in this mixture decreases with the waste rock proportion [8]. Wickland and Wilson [9] investigated the self-consolidation of tailingwaste rock mixture at different mixing ratios by using an analog device. The mixture underwent a relatively fast selfconsolidation when the waste rock-to-tailing ratio was $5: 1$. Tian et al. [10] evaluated the powder percentage in the block filling of a subsidence area at Jinshandian Iron Ore Mine and the probability of deris flow occurrence. Results suggested 
that using the cement block and waste rock mixture to fill the subsidence area can ensure safety. Tian et al. [11] found that the soil-rock mixture tends to be strong with the increase in rock content and strength, and its mechanical properties primarily depend on soil in the mixture when the rock proportion is less than $40 \%$.

Theoretical research on the shear strength of in situ fills should be conducted because the data from laboratory experiments cannot reflect their mechanical properties. Fill materials used to fill subsidence areas are typical granular materials with a wide range of grain sizes, and their shear strength mainly depends on the friction between grains [12-14]. Adhesive friction theory is an important basis for explaning the formation mechanism of soil and rock shear strengths [15]. Horne [16] and Penman [17] provided analytic relationships between the macroscopic shear and intergranular friction strengths. Sun et al. [18] investigated the influences of waste rock content and grain size on the shear strength of a fill for subsidence areas and explained the formation of fill shear strength on the basis of adhesive friction theory. However, they failed to provide a shear strength calculation model. Tong et al. [19] developed a method for calculating the shear strength of structural planes on the basis of adhesive friction theory and proved that this method is more reliable than the strength reduction method. In the present study, a model for calculating the shear strength of fills for subsidence areas was constructed on the basis of adhesive friction theory. Then, a theoretical calculation was performed using this model, and a verification experiment was conducted. This study aimed to find a reasonable method for determining the shear strength of fills used to restore subsided lands.

A force chain network can form in granular materials, such as soil and rock, to transfer forces when they are subjected to an external load. Considering that the forces between grains within this network are significantly greater than those between grains located outside this network, the macroscopic shear strength of granular materials are determined by the friction strength between grains within the force chain network $[15,20,21]$. Studies of [15] demonstrated that the macroscopic shear strength of granular materials depends on the friction between grains. The fills used for subsidence areas are often prepared by mixing waste rock and tailings. CT scans of the mixture samples containing different waste rock proportions (Figure 1) show that the waste rock and tailing grains are randomly distributed in the samples, and the fill is a typical granular composite with a wide range of grain sizes. This condition suggests that the shear strength of the fill is determined by the friction strength between the grains in it $[18,22,23]$.

\section{Theory}

2.1. Adhesive Friction Theory. Adhesive friction theory states that the frictional strength of soil and rock is essentially a molecular behavior in physics, roughness is an inherent quality of all surfaces of objects regardless of their smoothness, and the contact between surfaces occurs at the microbulges scattered on them (Figure 2). In the beginning, when two surfaces come into contact, the microbulges experience considerable stress caused by the normal forces $N_{S}$ between the surfaces. After the contact stress reaches its yield strength $\sigma_{y}$, the microbulges experience plastic deformation. As other smaller microbulges gradually come into contact, the contact area between the surfaces continues to increase until the net forces at the contact points reach zero. At this point, firm adhesion occurs between the microbulges in contact. For an ideal elastic-plastic material, the actual total contact area between the plastically deformed microbulges on particle surfaces can be expressed as $A_{r}=N_{S} / \sigma_{y}$. Intergranular friction $T_{S}$ is the product of $A_{r}$ and frictional strength $\tau_{\text {sf }}$, where $T_{S}=A_{r} \tau_{\text {sf }}$.

The classical theory of adhesive friction only considers the actual contact area but ignores the increase in the actual contact area caused by the relative slipping between the objects in contact. The modified theory of adhesive friction states that the normal force and friction can cause microbulges to yield and adhesive contact nodes to grow, and the actual contact area can be written as

$$
A_{r}^{2}=\left(\frac{N_{s}}{\sigma_{y}}\right)^{2}+\alpha\left(\frac{T_{s}}{\sigma_{y}}\right)^{2},
$$

where $\alpha$ is the experimentally determined coefficient, which is larger than 1 and normally at 9 . The coefficient $\alpha$ is usually affected by material properties, section shape, and other factors and is usually selected according to experience.

2.2. Shear Strength Theory of a Backfill Body. Sun et al. $[12,18,24]$ investigated the mechanism of shear strength of a backfill body based on the modified theory of adhesive friction. The changes in the grain size and proportion of waste rock and external pressure led to variations in the actual contact area between the grains in the backfill body, intergranular friction strength, and macroscopic shear strength of the backfill body. Therefore, the variation in the actual contact area should be first considered when constructing a shear strength model for a backfill body.

\subsubsection{Variation in the Actual Contact Area of the Backfill} Body Undergoing Shearing. The actual contact area between shear planes $A_{r}$ is considerably smaller than the nominal area of apparent shear plane $A_{0}$. Formula (1) suggests that $A_{r}$ arises from the adhesive friction between the shear planes in the fill and varies with shear displacement. $A_{r}$ is divided into adhesive contact area $A_{\mathrm{rm}}$ and contact area reduction caused by shear displacement, $A_{\mathrm{rb}} . A_{\mathrm{rm}}, A_{\mathrm{rb}}$, and $A_{r}$ are, respectively, given by [19]

$$
\begin{aligned}
& A_{\mathrm{rm}}=\sqrt{\left(\frac{N_{s}}{\sigma_{y}}\right)^{2}+\alpha\left(\frac{T_{s}}{\sigma_{y}}\right)^{2}}, \\
& A_{\mathrm{rb}}=-\frac{2 \lambda A_{\mathrm{rm}}}{\sqrt{A_{0}}-2 S} \cdot S,
\end{aligned}
$$




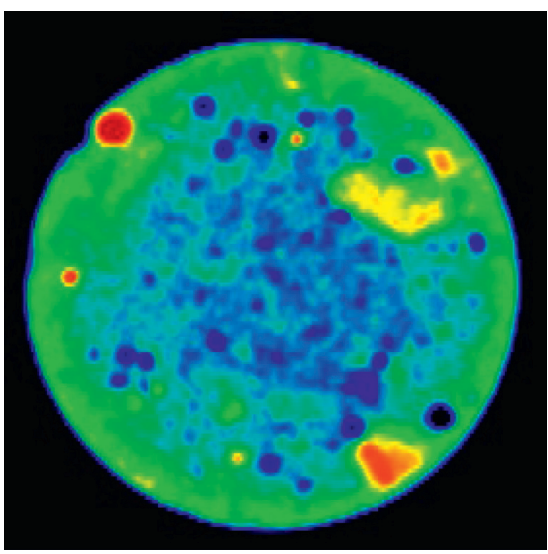

(a)

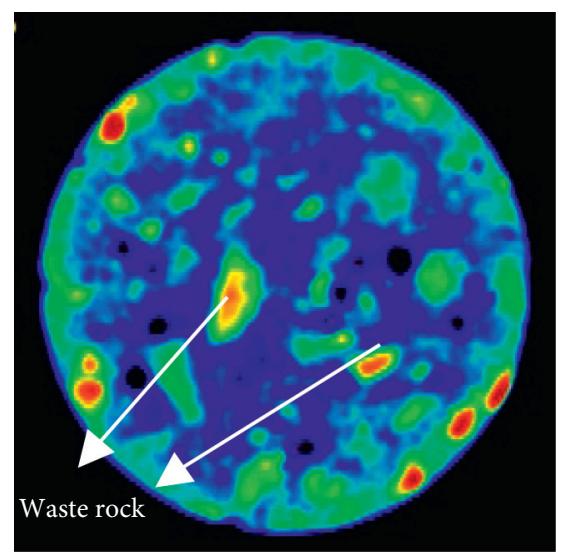

(b)

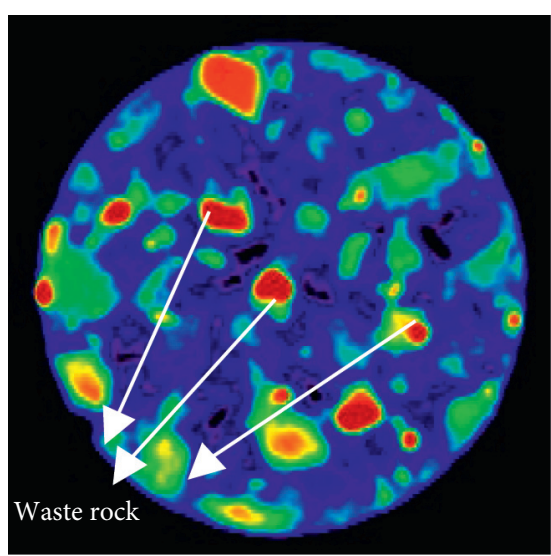

(c)

FiguRE 1: X-ray CT scan images of the backfill body with different mixture ratios [18], (a) waste rock content of 10\%, (b) waste rock content of $30 \%$, and (c) waste rock content of $50 \%$.

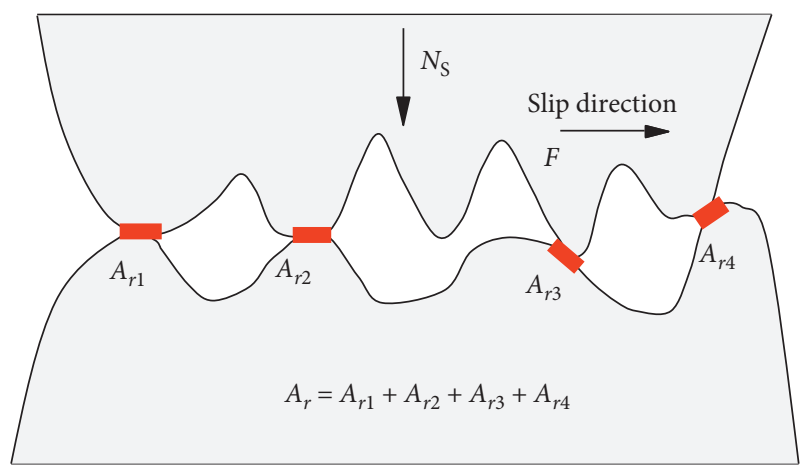

FIGURE 2: Schematic of intergranular contact [12].

$$
A_{r}=A_{\mathrm{rm}}+A_{\mathrm{rb}}=\sqrt{\left(\frac{N_{s}}{\sigma_{y}}\right)^{2}+\alpha\left(\frac{T_{s}}{\sigma_{y}}\right)^{2}} \cdot\left(1-\frac{2 \lambda A_{\mathrm{rm}} S}{\sqrt{A_{0}}-2 S}\right),
$$

where $S$ is the shear displacement, $\lambda$ is the modified coefficient of adhesive friction $\left(\lambda=\sqrt{A_{0}} / S_{m}\right.$, in which $S_{m}$ is the shear displacement when the shear stress exceeds the shear yield strength, $S_{m}=20 \mathrm{~mm}$ ), and $\alpha$ is a coefficient (normally $\alpha=9$ ).

\subsubsection{Determination of Shear Strength Based on Adhesive} Friction Theory. Adhesive friction theory states that the contact nodes on the shear planes are in a plastic state when the backfill body undergoes shearing. At a constant vertical stress, the friction between the shear planes is directly proportional to the actual contact area $A_{r}$. The friction between shear planes reaches its peak when $A_{r}$ reaches $A_{\text {rmax }}$, indicating that the shear strength at this point can be the maximum shear strength of the backfill body. Therefore, letting $A_{r}=A_{\mathrm{rmax}}$ at point $\left(S_{a}, N_{a}\right)$ in the stress-strain curve $N(s)$ of the backfill body, the following relation can be obtained:

$$
\begin{aligned}
\frac{\mathrm{d} A_{r}}{\mathrm{~d} s} & =0, \\
\frac{\mathrm{d}^{2} A_{r}}{\mathrm{~d} s^{2}} & <0 .
\end{aligned}
$$

Taking the derivative of $A_{r}$ with respect to $s$ provides $\frac{\mathrm{d} A_{r}}{\mathrm{~d} s}=\frac{\alpha T}{\sqrt{N^{2}+\alpha T^{2}} \sigma_{y}} \frac{\mathrm{d} T}{\mathrm{~d} s}\left(1-\frac{2 \lambda s}{\sqrt{A_{0}}-2 s}\right)-\frac{\sqrt{N^{2}+\alpha T^{2}}}{\sigma_{y}} \frac{2 \lambda \sqrt{A_{0}}}{\left(\sqrt{A_{0}}-s\right)^{2}}$.

Letting $\mathrm{d} A_{r} / \mathrm{d} s=0$ provides

$$
\frac{\alpha T}{N^{2}+\alpha T^{2}} \frac{\mathrm{d} T}{\mathrm{~d} s}=\frac{2 \lambda \sqrt{A_{0}}}{\left(\sqrt{A_{0}}-s\right)\left[\sqrt{A_{0}}-2(\lambda+1) s\right]} .
$$

The expression of $N(s)$ cannot be obtained because the initial value conditions of Formula (7) are unavailable. On this basis, the related measured data are used in Formula (7) to acquire point $\left(S_{j} N_{j}\right)\left(j=1 \cdots\right.$ that satisfies $\mathrm{d} A_{r} / \mathrm{d} s=0$. Then, $\mathrm{d}^{2} A_{r} / \mathrm{d} s^{2}<0$ at point $\left(S_{j} N_{j}\right)$ is evaluated to determine the point that satisfy the condition, $\left(S_{a} N_{a}\right)$. At this point, $A_{r}$ reaches its maximum, the friction forces between shear planes reach their peak, and the corresponding shear strength, namely, adhesive friction strength $\tau_{p}$, is obtained.

\section{Experimental}

3.1. Direct Shear Test. A small modified direct shear apparatus was used to test the fill samples. The samples with $6.18 \mathrm{~cm}$ diameter and $5.0 \mathrm{~cm}$ height were obtained from tailings and waste rock in a mine. The waste rock particles have an important influence on the shear strength [25], so the waste rock was pulverized into three groups of fragments, which had grain sizes of $-20,-15$, and $-10 \mathrm{~mm}$, respectively. Considering the limited size of the shear cell, supersize waste rock was treated through equivalent substitution to ensure the continuous distribution of grain sizes.

In the experiment, mixture samples containing $10 \%$, $20 \%, 30 \%$, and $40 \%$ waste rock were prepared by mixing the 


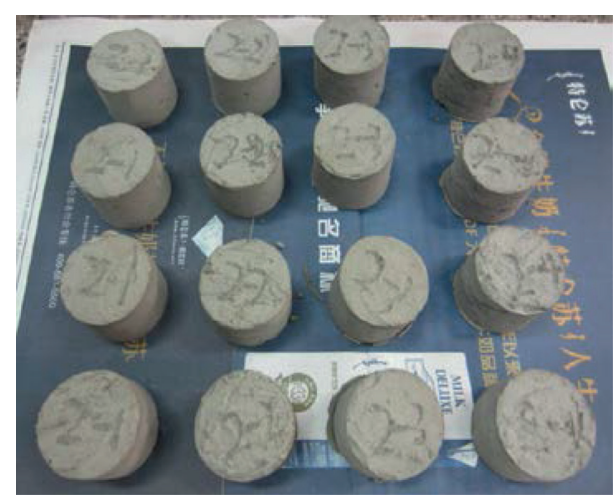

(a)

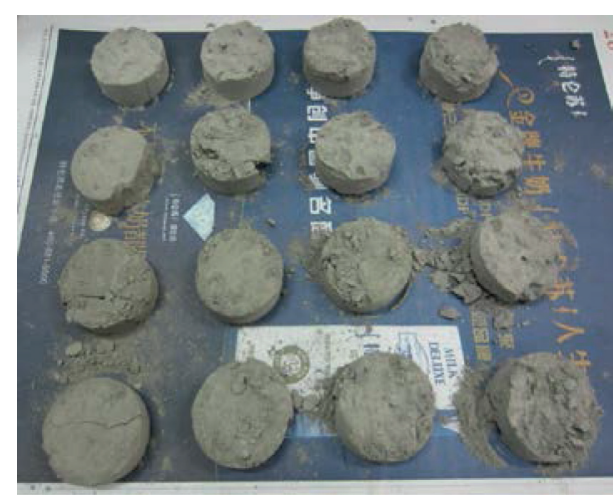

(b)

Figure 3: Shear test photos: (a) prepared specimens; (b) specimens destroyed.

TABLE 1: Results of the shear strength test $(\mathrm{kPa})$.

\begin{tabular}{|c|c|c|c|c|c|c|c|}
\hline \multirow{2}{*}{ Waste rock proportion (\%) } & \multirow{2}{*}{ Grain size $(\mathrm{mm})$} & \multicolumn{4}{|c|}{ Vertical pressure $(\mathrm{kPa})$} & \multirow{2}{*}{$c(\mathrm{kPa})$} & \multirow{2}{*}{$\varphi\left({ }^{\circ}\right)$} \\
\hline & & 100 & 200 & 300 & 400 & & \\
\hline \multirow{3}{*}{40} & -20 & 167 & 245 & 341 & 444 & 67.3 & 42.8 \\
\hline & -15 & 158 & 220 & 335 & 408 & 64.3 & 40.8 \\
\hline & -10 & 144 & 236 & 305 & 399 & 50.7 & 40.6 \\
\hline \multirow{3}{*}{30} & -20 & 153 & 239 & 338 & 436 & 54.3 & 43.5 \\
\hline & -15 & 144 & 215 & 329 & 401 & 51 & 41.5 \\
\hline & -10 & 132 & 187 & 277 & 353 & 48.5 & 37 \\
\hline \multirow{3}{*}{20} & -20 & 144 & 235 & 308 & 367 & 77.5 & 36.6 \\
\hline & -15 & 142 & 214 & 276 & 344 & 77.3 & 33.7 \\
\hline & -10 & 139 & 189 & 265 & 329 & 68.7 & 32.9 \\
\hline \multirow{3}{*}{10} & -20 & 157 & 241 & 317 & 388 & 83.2 & 37.5 \\
\hline & -15 & 150 & 236 & 290 & 369 & 83.8 & 35.3 \\
\hline & -10 & 147 & 212 & 272 & 330 & 87.5 & 31.4 \\
\hline
\end{tabular}

waste rock of each grain size with tailings and water, and the mass concentration ranges from $81 \%$ to $83 \%$. The prepared paste was poured into molds with $6.2 \mathrm{~cm}$ diameter and $5.0 \mathrm{~cm}$ height. After the samples were fully air-dried at room temperature, they were released from the molds for the direct shear test. During the direct shear test, vertical stresses of $100,200,300$, and $400 \mathrm{kPa}$ were applied to each sample successively, and a lateral shear stress was rapidly applied until shear failure occurred in each sample (Figure 3).

3.2. Test Results. The direct shear test was conducted on 12 groups of samples. Table 1 shows the test results, and Figure 4 shows the shear stress-shear strain curves of some samples. The shear strength of the samples increased with the increase in vertical stress. As the proportion of waste rock increased, the shear strength initially decreased and then increased, and the minimum values were reached when the waste rock proportion was $20 \%$ or $30 \%$. The cohesion force continuously declined, and the internal friction angle gradually increased. At the same waste rock proportion, the increase in waste rock grain size increased the shear strength, cohesion force, and internal friction angle.

Shear strength normally includes two components, namely, adhesive and frictional strengths. The calculation results indicated that the frictional strength accounted for approximately $80 \%$ of the shear strength of the backfill body and was the dominant component of shear strength. The sample containing $30 \%$ waste rock with a grain size of $-20 \mathrm{~mm}$ displayed a frictional strength of $381.31 \mathrm{kPa}$, which was equivalent to $87.52 \%$ of its total shear strength.

\section{Results and Discussion}

The data from the experiment were substituted into the aforementioned formulas for calculating the contact area change and shear strength, and the theoretical and experimental values of shear strength were compared.

4.1. Actual Contact Area in the Backfill Body. The relationship of shear displacement with $A_{\mathrm{rm}}, A_{\mathrm{rb}}$, and $A_{r}$ was derived by using the experimental data from the test (in which the waste rock grain size was $-20 \mathrm{~mm}$, the waste rock proportion was $30 \%$, and the vertical stress was $400 \mathrm{kPa}$ ) and the related data in the stress-strain curve into formulas (2), (3), and (4), as shown in Figure 5.

As presented in Figure 5, adhesive contact area $A_{\mathrm{rm}}$ increased with the shear displacement, and the rate of increase began to decline when $A_{\text {rm }}$ approached $0.3 \mathrm{~cm}^{2}$. The contact area reduction caused by shear displacement $A_{\mathrm{rb}}$ increased with the shear displacement. The rate of increase 


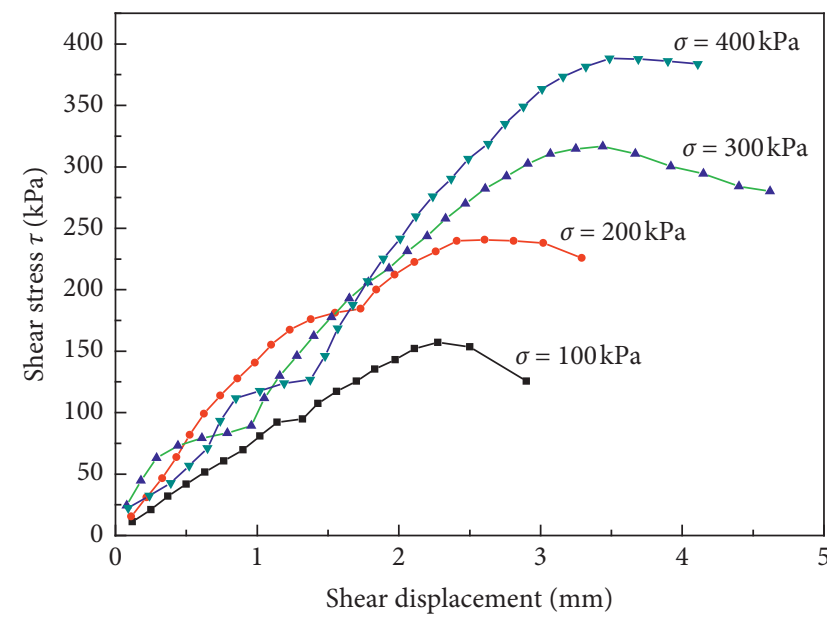

(a)

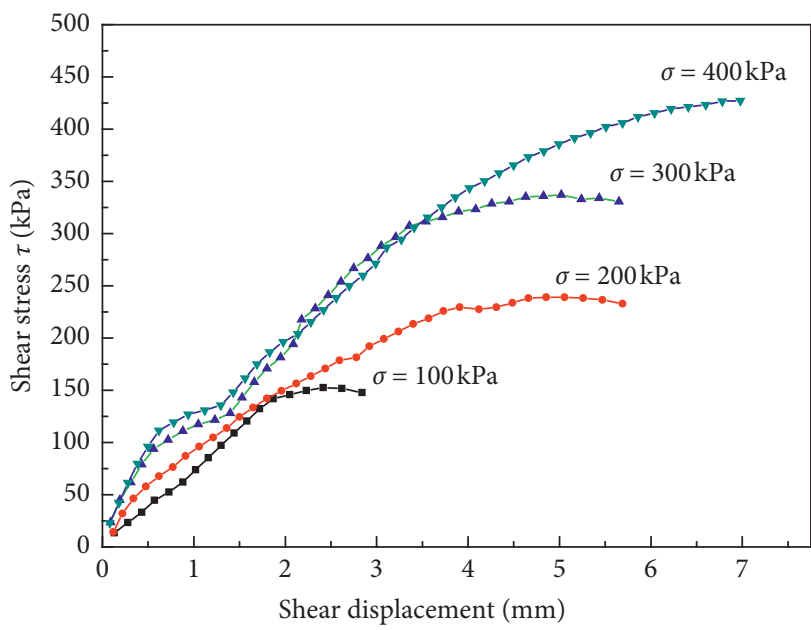

(c)

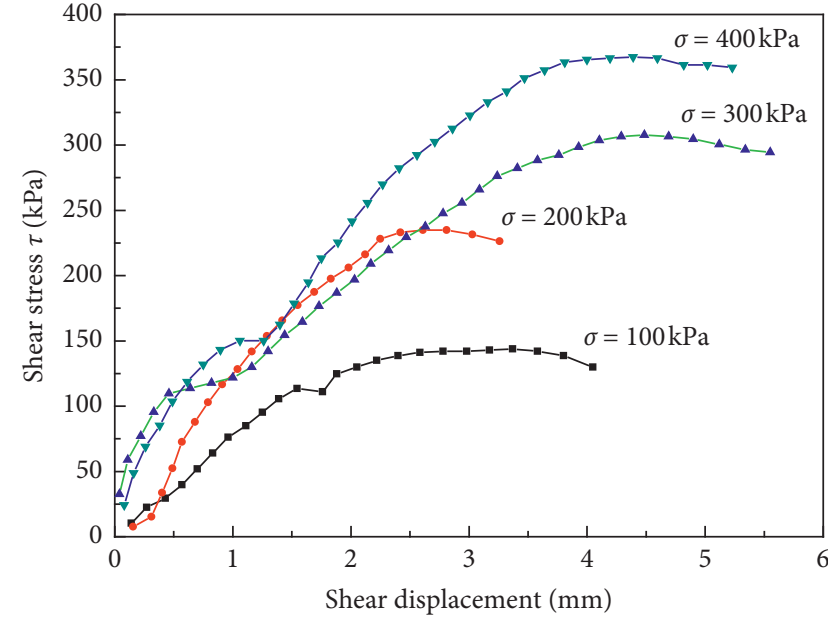

(b)

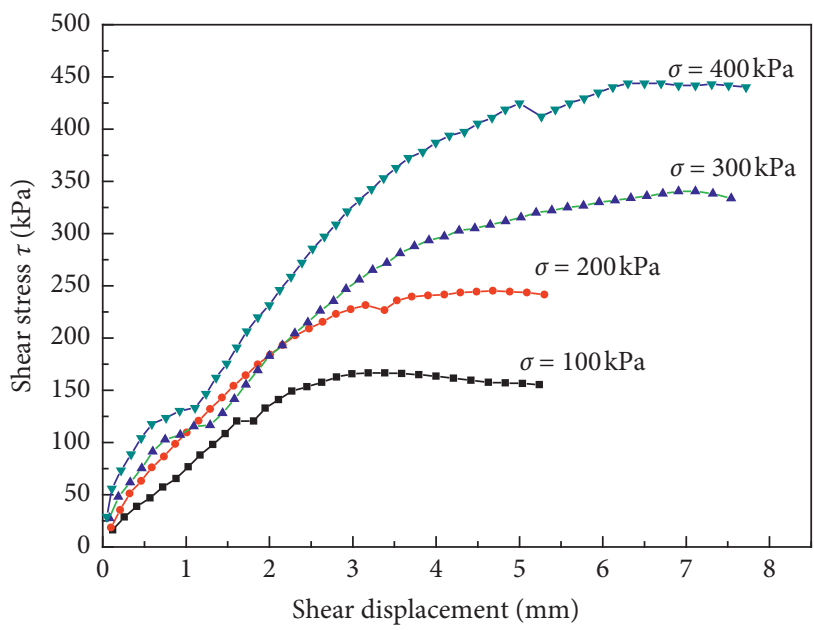

(d)

FIGURE 4: Shear stress-shear displacement curves of backfill body samples $(-20 \mathrm{~mm})$ : (a) waste rock content of $10 \%$, (b) waste rock content of $20 \%$, (c) waste rock content of $30 \%$, and (d) waste rock content of $40 \%$.

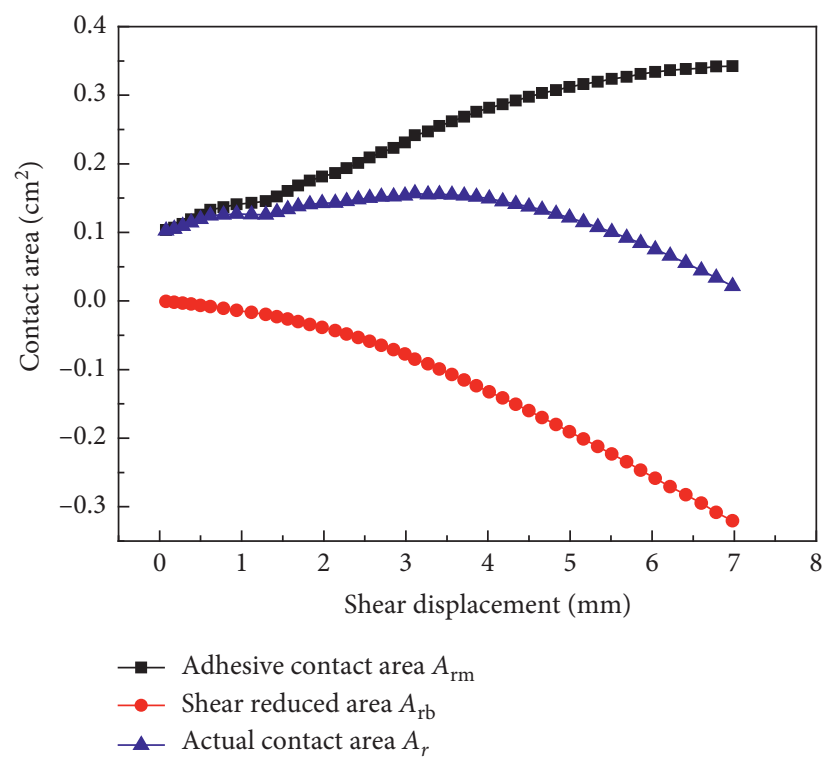

FIgURE 5: Relationship between shear displacement and the contact area. 


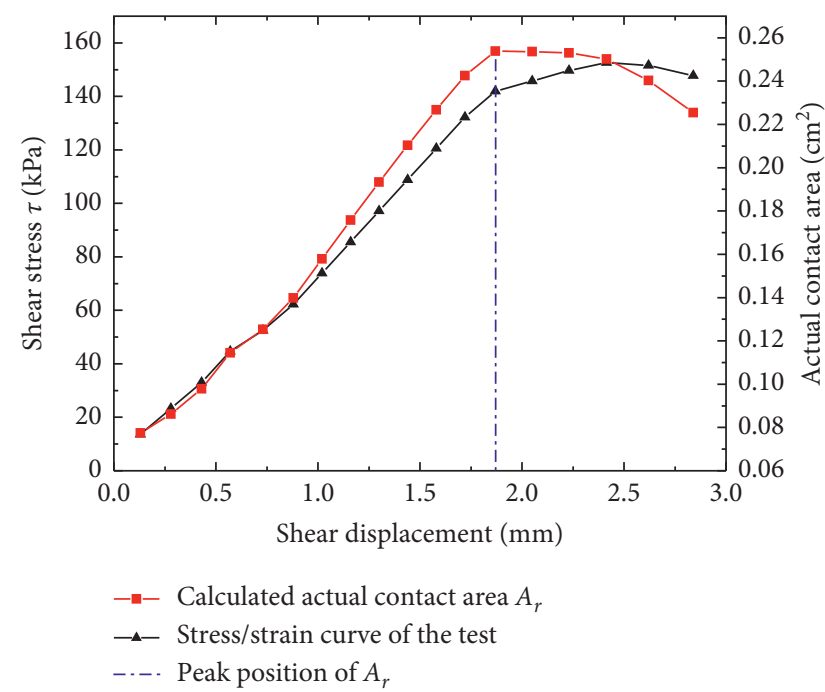

(a)

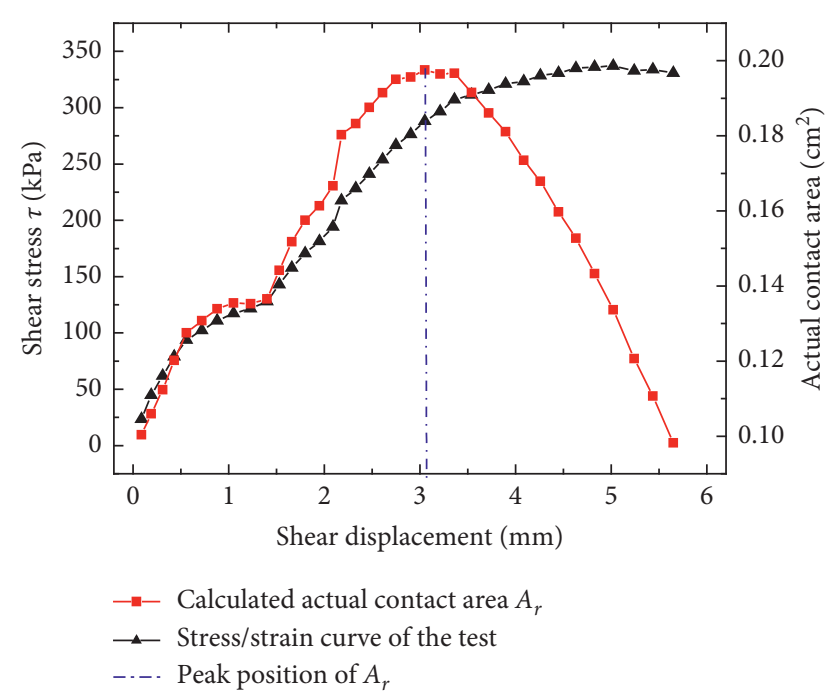

(c)

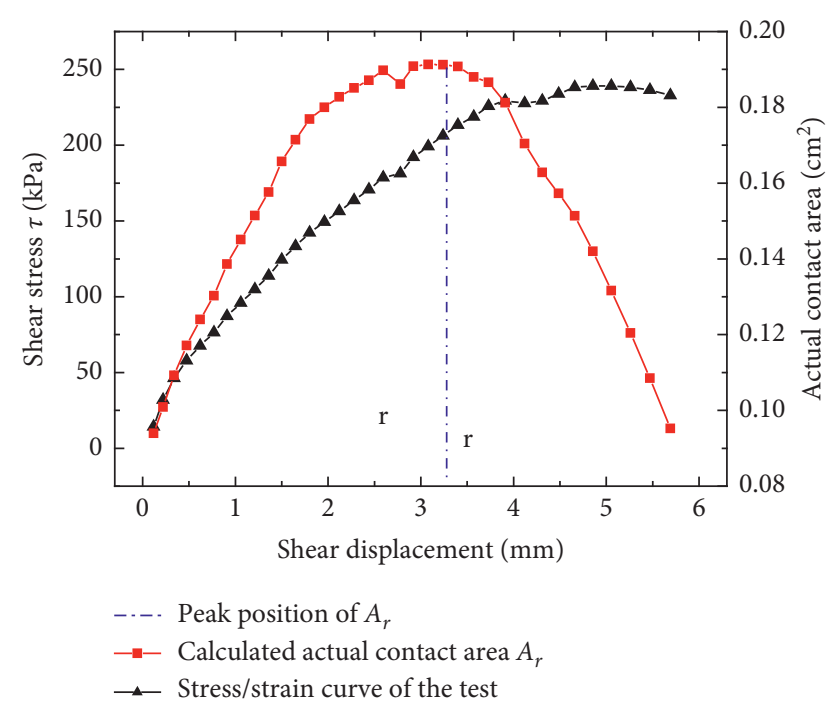

(b)

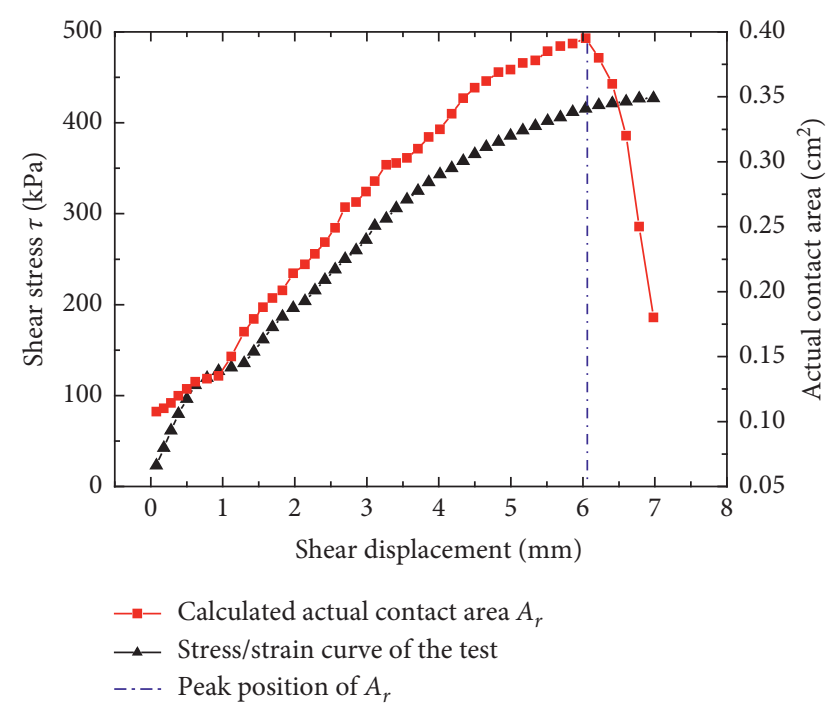

(d)

FIGURE 6: Relationship between shear strength and actual contact area: (a) vertical stress $100 \mathrm{kPa}$, (b) vertical stress $200 \mathrm{kPa}$, (c) vertical stress $300 \mathrm{kPa}$, and (d) vertical stress $400 \mathrm{kPa}$.

was relatively low when the shear displacement was smaller than $1.5 \mathrm{~mm}$ and began to grow when the shear displacement exceeded $1.5 \mathrm{~mm}$. The actual contact area $A_{r}$ increased and then decreased with the shear displacement and exhibited a maximum at $A_{\text {rmax }}$. The shear strength reached its peak at $A_{\text {rmax }}$, and the corresponding shear strength obtained through calculation was considered the maximum shear strength of the backfill body.

4.2. Shear Strength Calculation. After $A_{\text {rmax }}$ was determined, the strength of adhesive friction $\tau_{p}$ was calculated using Formula (7). Then, the relationship between shear strength and the actual contact area was obtained using the experimental data from the tests (in which the waste rock grain size was $-20 \mathrm{~mm}$, the waste rock proportion was $30 \%$, and the vertical stresses were $100,200,300$, and $400 \mathrm{kPa}$ ) into the formula, as shown in Figure 6.

As presented in Figure 6, the samples demonstrated theoretical adhesive friction strengths of 141.9, 218.7, 288.1, and $415.6 \mathrm{kPa}$, which were $92.7 \%, 91.5 \%, 85.23 \%$, and $95.3 \%$ of the experimental values of maximum shear strength, respectively, when the waste rock grain size was $-20 \mathrm{~mm}$, waste rock proportion was $30 \%$, and vertical stresses were $100,200,300$, and $400 \mathrm{kPa}$. Therefore, the calculated values of adhesive friction strength were smaller than the corresponding experimental values of shear strength.

4.3. Factors Influencing the Theoretical Adhesive Friction Strength. Fills used to restore subsided lands are a typical type of granular composites made from waste rock and 


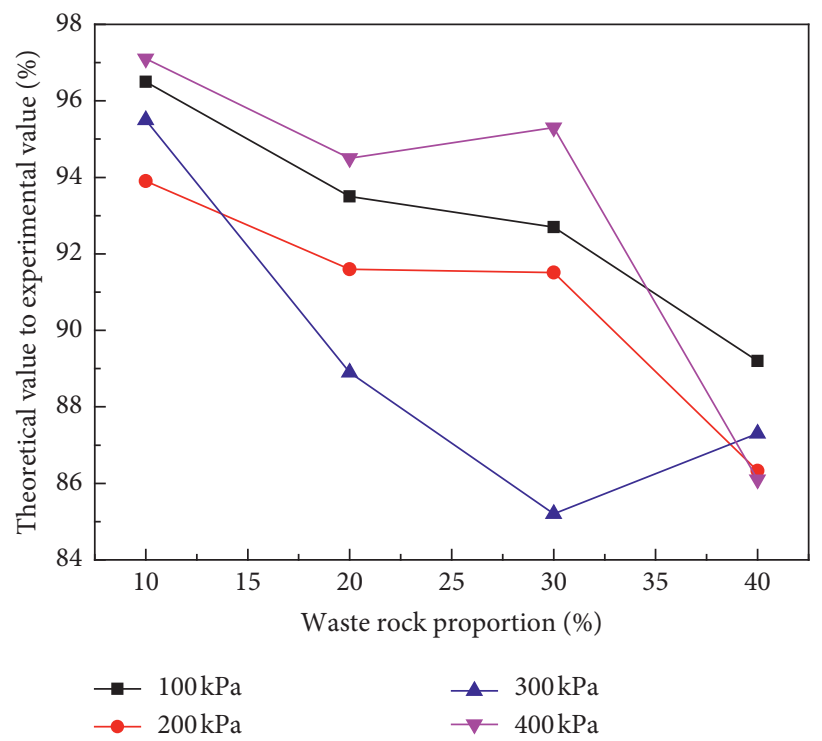

FIGURE 7: Relationship between the waste rock proportion and the ratio of the theoretical value to experimental value of shear strength.

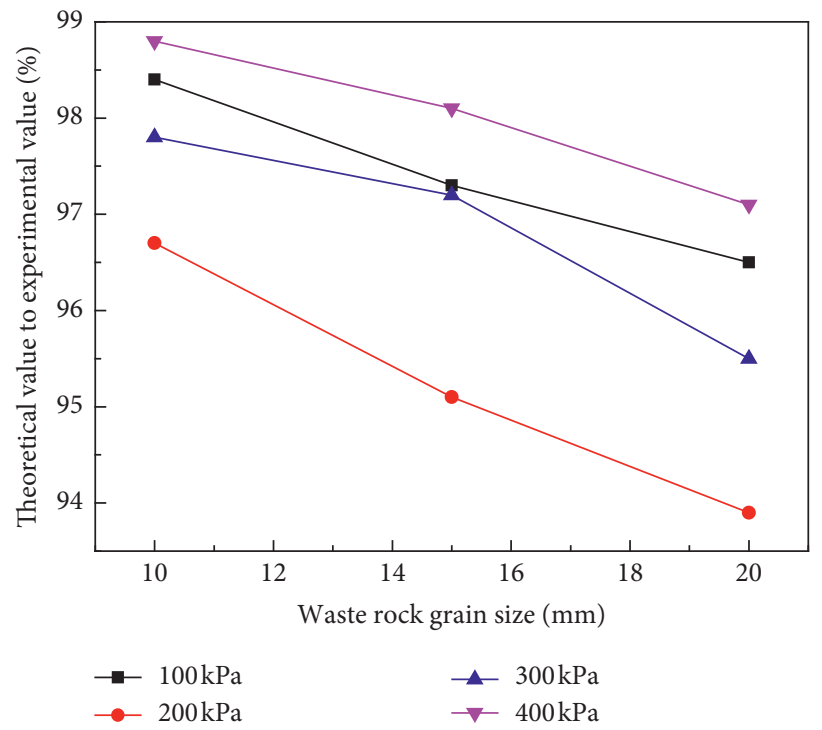

FIGURE 8: Relationship between waste rock grain size and the ratio of the theoretical value to experimental value of shear strength.

tailings. The variation pattern of the difference between the theoretical and experimental values of adhesive friction strength varied between samples with different mixing ratios. As shown in Figure 7, the theoretical values of shear strength were close to the experimental values when the waste rock proportion was low, and their differences increased with the increase in waste rock proportion. The relationship between vertical stress and theoretical shear strength did not exhibit an evident pattern. As the waste rock grain size increased, the difference between the theoretical and experimental results exhibited a continued increase, and its relationship with vertical stress did not exhibit a pattern, as shown in Figure 8.

The results suggest that the proposed shear strength calculation method based on adhesive friction theory is applicable to homogeneous granular materials, and the values calculated using the method are close to the experimental results. Considering that the theoretical values of shear strength were smaller than the experimental values, they can be used in practical applications to ensure the stability of in situ fills for subsidence areas. 


\section{Conclusions}

In this study, a shear strength calculation method for the backfill body used to fill subsidence areas was developed on the basis of adhesive friction theory, and a verification experiment was conducted in the laboratory. The theoretical calculation results were compared with experimental results. This study presents the following conclusions:

(1) Actual contact area $A_{r}$ is divided into two components, namely, adhesive contact area $A_{\text {rm }}$ and contact area reduction caused by shear displacement, $A_{\mathrm{rb}}$. Actual contact area $A_{r}$ exhibited a maximum at $A_{\text {rmax }}$, and the shear strength reached its peak at this point. Then, the corresponding shear strength obtained through calculation was considered the maximum shear strength of the backfill body.

(2) The values of shear strength calculated based on adhesive friction theory were smaller than those obtained from the laboratory experiment. The theoretical values of shear strength were close to the experimental values when the waste rock proportion was low, and their differences increased with the increase in waste rock proportion. The increase in waste rock grain size increased the differences between the theoretical and experimental results.

(3) The shear strength calculation model based on adhesive friction theory applies to homogeneous mixtures. This model can be used to estimate the maximum shear strength of in situ fills and in related computational analyses.

This study presents a preliminary discussion of the theoretical method for calculating the shear strength of fills used to restore subsided grounds. Although further corrections and improvement are necessary, this research can provide a new insight into the theoretical shear strength of materials with a wide range of grain sizes, such as the waste rock-tailing mixture. The results of theoretical calculation, combined with the results of laboratory experiments, can provide support for the proper determination of the shear strength of fills used to restore subsided lands.

There are still some deficiencies in this study, which need to be improved in the future. Firstly, a lot of experiments are carried out to improve the theoretical model; secondly, field in situ experiments are carried out to make up for the shortcomings of small-scale tests; finally, the effects of parameters such as the amount of waste rock added, the size of waste rock particles, and the shear rate on the shear strength are studied.

\section{Data Availability}

The data used to support the findings of this study are included within the article.

\section{Conflicts of Interest}

The authors declare that they have no conflicts of interest regarding the publication of this paper.

\section{Authors' Contributions}

Lei Liu and Wei Sun designed experiments; Wei Sun and Shengyou Zhang carried out the experiments; Jinxin Li analyzed the experimental results; Weidong Liu analyzed the data and developed analysis tools; and Wei Sun and Lei Liu wrote the manuscript.

\section{Acknowledgments}

This research was supported by the National Natural Science Foundation of China (Grant nos. 51964023, 11862010, and 51864023).

\section{References}

[1] F. He, Y. N. Xu, and G. Qiao, "Distribution characteristics of mine geological hazards in China," Geological Bulletin of China, vol. 31, pp. 476-485, 2012.

[2] S. Cao, G. Xue, and E. Yilmaz, "Flexural behavior of fiber reinforced cemented tailings backfill under three-point bending," IEEE Access, vol. 7, pp. 139317-139328, 2019.

[3] H. Chen, Z. M. Sun, and G. H. Yao, "Feasibility study on the program of eliminating potential accident at veinlet belt orebody of Tongkeng mine," China Mineralogical Magazine, vol. 17, pp. 100-106, 2008.

[4] H. Lu, C. Qi, Q. Chen, D. Gan, Z. Xue, and Y. Hu, “A new procedure for recycling waste tailings as cemented paste backfill to underground stopes and open pits," Journal of Cleaner Production, vol. 188, pp. 601-612, 2018.

[5] Y. B. Hou, J. Tang, and S. X. Wei, "Research on tailings cementation and discharging technology," Metal Mine, vol. 6, pp. 59-62, 2011.

[6] Z. Yin, W. Chen, H. Hao et al., "Dynamic compressive test of gas-containing coal using a modified split hopkinson pressure bar system," Rock Mechanics and Rock Engineering, vol. 53, no. 2, pp. 815-829, 2020.

[7] W. Sun, H. Wang, and K. Hou, "Control of waste rock-tailings paste backfill for active mining subsidence areas," Journal of Cleaner Production, vol. 171, pp. 567-579, 2018.

[8] M. Leduc and M. E. Smith, "Tailings co disposal-innovation for cost saving and liability reduction," Latin America Mining Record, vol. 16, pp. 1-15, 2003.

[9] B. E. Wickland and G. W. Wilson, "Self-weight consolidation of mixtures of mine waste rock and tailings," Canadian Geotechnical Journal, vol. 42, no. 2, pp. 327-339, 2005.

[10] Y. H. Tian, X. C. Li, and N. Wei, "Experimental study of characteristics of compression and pulverization for cemented tailings blocks," Rock and Soil Mechanics, vol. 32, pp. 3597-3603, 2011.

[11] H. N. Tian, Y. Y. Jiao, and H. Wang, "Research on biaxial test of mechanical characteristics on soil-rock aggregate (SRA) based on particle flow code simulation," Chinese Journal of Rock Mechanics and Engineering, vol. 34, pp. 3564-3573, 2013.

[12] W. Sun, A. X. Wu, and H. J. Wang, "Experimental research on shear behavior of subsidence backfill body mixed by unclassified tailings and waste rocks," Chinese Journal of Rock Mechanics and Engineering, vol. 32, pp. 917-925, 2013.

[13] Z. Q. Yin, Z. X. Hu, Z. D. Wei et al., "Assessment of blastinginduced ground vibration in an open-pit mine under different rock properties," Advances in Civil Engineering, vol. 2018, Article ID 4603687, 10 pages, 2018. 
[14] S. Cao and W. Song, "Effect of filling interval time on the mechanical strength and ultrasonic properties of cemented coarse tailing backfill," International Journal of Mineral Processing, vol. 166, pp. 62-68, 2017.

[15] C. Thornton and L. Zhang, "On the evolution of stress and microstructure during general $3 \mathrm{D}$ deviatoric straining of granular media," Géotechnique, vol. 60, no. 5, pp. 333-341, 2010.

[16] M. R. Horne, "The behaviour of an assembly of rotund, rigid, cohesionless particles. III," Proceedings of the Royal Society of London. A. Mathematical and Physical Sciences, vol. 310, no. 1500, pp. 21-34, 1969.

[17] A. D. M. Penman, "Shear characteristics of a saturated silt, measured in triaxial compression," Géotechnique, vol. 3, no. 8, pp. 312-328, 1953.

[18] W. Sun, A. Wu, K. Hou, Y. Yang, L. Liu, and Y. Wen, "Realtime observation of meso-fracture process in backfill body during mine subsidence using X-ray CT under uniaxial compressive conditions," Construction and Building Materials, vol. 113, pp. 153-162, 2016.

[19] Z. Y. Tong, C. X. Chen, and J. Xu, "Selection of shear strength of structural plane based on adhesion friction theory," Chinese Journal of Geotechnical Engineering, vol. 30, pp. 1367-1371, 2008.

[20] X. Z. Li, C. Z. Qi, Z. S. Shao, and C. Xia, "Effects of crack inclination on shear failure of brittle geomaterials under compression," Arabian Journal of Geosciences, vol. 10, no. 23, pp. 529-541, 2017.

[21] C.-P. Lu, Y. Liu, T.-B. Zhao, and H.-Y. Wang, "Experimental research on shear-slip characteristics of simulated fault with zigzag-type gouge," Tribology International, vol. 99, pp. 187197, 2016.

[22] M. Wang, L. Liu, X.-Y. Zhang, L. Chen, S.-Q. Wang, and Y.-H. Jia, "Experimental and numerical investigations of heat transfer and phase change characteristics of cemented paste backfill with PCM," Applied Thermal Engineering, vol. 150, pp. 121-131, 2019.

[23] L. Liu, C. Zhu, C. Qi, B. Zhang, and K.-I. Song, "A microstructural hydration model for cemented paste backfill considering internal sulfate attacks," Construction and Building Materials, vol. 211, pp. 99-108, 2019.

[24] W. Sun, K. Hou, and Z. Y. Yang, "X-ray CT three-dimensional reconstruction and discrete element analysis of the cement paste backfill pore structure under uniaxial compression," Construction and Building Materials, vol. 138, pp. 69-78, 2017.

[25] C. S. Wen, V. Marzulli, F. Cafaro, K. Senetakis, and T. Pöschel, "Micromechanical behavior of DNA-1A lunar regolith simulant in comparison to ottawa sand," Journal of Geophysical Research: Solid Earth, vol. 124, no. 8, pp. 8077-8100, 2019. 